\title{
Concepção Tomista do Direito Natural
}

\section{I I}

\section{Alexandre Correia}

Ao terminar o segundo artigo dissemos que, salvo o ponto de partida, da doutrina tomista do direito natural, não é possível levar mais longe o relativismo da ordem jurídica (1). Mas por êsse ponto de partida - a moralidade objectiva - S. Tomás escapa ao êrro do puro fenomenismo.

A moralidade objectiva é a verdade objectiva da ordem ética. Ora, na ordem lógica, devemos distinguir a verdade em matéria necessária ou natural, impossível ou remota e possível ou contingente. Quando o predicado convém per se ao sujeito, a proposição é em matéria necessária; assim, se dissermos - o homem é animal, ou, tem a faculdade de rir-se. Ao contrário, quando o predicado repugna per se ao sujeito, o enunciado é em matéria impossível ou remota; p. ex., êste -o homem é asno. Se enfim, num meio termo, predicado e sujeito não são entre si repugnantes nem convenientes per se, o enunciado recai sôbre ma-

(1) Cf. Rev. da Fac. de Dto., vol. XXXVI, fascs. I e II, janeiroagosto, 1941. Ao leitor a quem porventura êstes estudos possam interessar lembramos, que o $10^{\circ}$ artigo apareceu no fasc. de janeiro a dezembro, 1940, pgs. 577-590. 
téria possível ou contingente; p. ex., Sócrates é filosofo, ou, Sócrates é Persa.

No primeiro e no segundo casos - juizos analíticos -, a simples análise do predicado revela a conveniência ou repugnância em relação ao sujeito. No terceiro, a repugnância ou conveniência é condicionada pela experiência; Kant denominaria êsses juizos sintéticos a posteriori. No primeiro caso e no segundo, a verdade dos juizos é objecti$v a$; isto é, o trabalho analítico da inteligência apenas consiste em descobrir a conveniência ou repugnância necessárias entre sujeito e predicado (2).

Ora, como a ordem moral é, segundo vimos, solidária e correlata da lógica, a moralidade também se apresenta como necessária ou natural, e contingente, tomando-se a expressão natural em sentido restrito, porque, como elucidamos, em sentido lato também o contingente é natural. Quando, na ordem prática, há relação moral necessária entre a nossa natureza racional e a perpetração de certos actos, essa relação moral é objectiva; no caso contrário, contingente. Assim, furtar, repugnando per se ao princípio sinderético fundamental, há adaequatio entre a proibição do furto e a nossa natureza racional; a lei que o proibe é, pois, em matéria moral necessária ou objectiva, como o é a que nos impõè o dever da justiça. Diferentemente, restituir os depósitos — exemplo já aduzido - não importando relação de conveniência ou repugnância essencial, per se, com o referido princípio, não pode constituir objecto de obrigação ético-jurídica natural objectiva, mas apenas contingente (3).

$\mathrm{O}$ relativismo natural de $\mathrm{S}$. Tomás supõe portanto um absoluto, que o funda e dirige. Não se esqueça porém, que êsse absoluto é contudo condicionado pelo facto da natureza humana; e isso mesmo fá-lo imergir na experiência. Um

(2) Cf. Peri Hermeneias, I, XIII, pr..

(3) Cf. Lotrin, Loi morale naturelle et loi positive, ed. cit., pgs. 6 e segs.. 
atento exame fará compreender que tal assêrto não encerra qualquer contradição.

Não sòmente. Projectará ainda intensa luz sôbre a difícil e controvertida questão de saber-se como o direito positivo deriva da lei natural.

Indagando a noção de direito positivo, S. 'Tomás encontra a divisão tripartida e romana, do direito, em natural, das gentes e civil; e procura conciliá-la com a aristotélica, da justiça.

Esta última é a seguinte. O justo político (politikón dikaion) é legal (nomikón) ou natural (physikón). Este apresenta em tôda parte a mesma natureza; aquele é o resultado de uma convenção (katá synthéken). Embora a natureza humana mesma não seja dotada de absoluta invariabilidade, não tem a mobilidade característica das instituições convencionais (4).

Ora, essa concepção S. ToMás, nos seus comentários à Ethica do Filósofo, a identifica com a divisão dos juristas romanos, que denominam jus ao que Aristóteles chama justum (dikaion), e bipartem o direito em natural e positivo. Há porém diferença em que Aristóteles deriva a denominação de justo ou civil (justum vel civile) do uso que dêle fazem os cidadãos, e os juristas romanos explicam o direito político ou civil (jus politicum vel civile) pela causa, pois é o direito que a cidade (civitas) para si constituíu. Assim, o chamado por A. justo legal (justum legale, nomikón díkaion) è o direito positivo (jus positivum), dos jurisconsultos, constituindo para êstes o direito civil parte do positivo.

(4) Eth. Nicom., 1134 b 18-1135 a; V. VII. Quem desejar conhecer melhor o pensamento de ARISTóteles sôbre a lei natural deverá ler todo o cap. VII. Bons comentários em S. ToMÁs; e nos modernos: J. Bunnet, The Ethics of Aristotle, London, Methuen, $1900 ;$ J. A. STEwart, Notes on the Nicomachean Ethics, Oxford, Clarendon Press, 1892, I, pgs. 492 e segs.; A. GRant, The Ethics of Aristotle, London, Longmans, 1874, II, pgs. 126 e segs. E ainda outros, como Ramsauer, em alemão. A bibliografia do assunto é vastíssima. 
Mas, continuando a comentar o pensamento do Filósofo, S. Tomás introduz a noção do ius gentium, do direito romano. Pois, diz, distinguimos no homem dupla natureza. Uma como animal, com inclinações comuns às dos animais. Outra racional, por onde distingue o honesto do desonesto.

Ora, Aristóteles funda em a natureza racional o justum naturale, fixo e invariável porque a natureza humana é em tôda parte a mesma: non oritur ex aliqua opinione humana, sed natura. E a sua causa se explica por comparação com a ordem especulativa. Nesta, duas espécies de princípios se distinguem: uns, os evidentes e indemonstráveis, com os seus derivados imediatos; outros, os descobertos pela inventiva humana e os que lhe estão proximamente ligados.

Assim também na ordem prática, in operativis, certos princípios são evidentes e como indemonstráveis, quasi indemonstrabilia, com suas conseqüências próximas como, evitar o mal, não prejudicar a ninguém, não furtar, e semelhantes; outros foram estabelecidos pela indústria humana - per industriam hominum excogitata.

A justiça fundada em a natureza racional do homem é o justo natural, o direito natural; a segunda, o justum legale sive positivum, o direito positivo.

Diversamente, os juristas romanos consideram direito natural, jus naturale, o que se funda em a natureza animal do homem; daí a famosa definição de Ulpiano, que S. Tomás tem presente, jus naturale est quod natura omnia animalia docuit (5). Mas, ao lado dessa natureza comum com os animais, tem o homem a sua própria, racional; e o direito que nela se funda é o jus gentium, quia eo omnes gentes utuntur (diz S. Tomás, com as palavras mesmas de Ulpiano e GaIo), sicut quod pacta sunt servanda, et quod legati apud hostes sint tuti, et alia hujusmodi. Ambas essas divisões porém se incluem no justum naturale de Aristóteles (6).

(5) D. 1.1.1.3

(6) Ethicorum. V, lect. XII. 
Como se vê, S. Tomás admite a divisão tripartida do direito privado em natural, das gentes e civil. Mas o seu esfôrço para aplicar a essa classificação romana a terminologia de Aristóteles levou-o a uma elaboração própria dêsses conceitos, não coincidentes em tudo com a idéia dos jurisconsultos romanos (7).

Em síntese, a idéia de S. Tomás, nascida da preocupação de conciliar entre si as concepções de Aristóteles e dos jurisconsultos romanos, pode se apresentar do modo seguinte.

A noção de direito (ius) ou de justiça (iustum) supõe um acto adequado a outrem de certo modo. Ora, essa adequação pode decorrer da própria natureza dos seres, (ex ipsa natura rei), como quando damos uma cousa em troca exactamente de outra; ou de uma convenção (ex condicto), como quando nos consideramos satisfeitos com o que recebermos. A primeira adequação funda o direito natural, (ius naturale); a segunda, o direito positivo (ius positivum) (8). Entre o direito natural e o positivo, participando de um e de outro, insere-se o direito das gentes, ius gentium.

o direito natural é susceptível de duplo sentido. Considerada a adequação a outrem - 1) de modo absoluto, secundum absolutam considerationem, temos o direito natural strictissimo modo, em sentido estritíssimo, que pode ser definido com Ulpiano - quod natura omnia animalia docuit. Nesta acepção podemos dizer, p. ex., que um sexo, sendo naturalmente adequado a outro, a procriação é de direito natural.

Mas a adequação - 2) pode fundar-se nas conseqüências racionalmente resultantes do justo natural; são umas como conclusões dos princípios imediatos da lei natural. Assim, a proibição de matar, defluente do princípio que

(7) A divisão tripartida do direito privado em ius naturale, gentium et civile, no direito romano, tivemos ocasião ḍe estudá-la demoradamente num opúsculo para o qual remetemos o leitor. (O conceito de i.n.,g., et c., no d.r., S. Paulo, Odeon, 1934).

(8) S. Th., 2., 2. 57.2.c. 
a ninguém é lícito fazer mal; os contratos, como o de compra e venda, sem os quais o homem não pode satisfazer à sua tendência naturalmènte social; a propriedade privada dos bens materiais; a monogamia.

Ora, essas instituições, derivadas da lei natural à guisa de conclusões próximas, constituem o domínio do direito das gentes, ius gentium. E assim considerado, o ius gentium pode ser definido, com Gaio, quasi quo jure omnes gentes utuntur. E' um direito natural especificamente humano - quod naturalis ratio inter omnes gentes constituit. Porque comparar e concluir é pró prio da razão; e assim a conclusão será natural, secundum rationem naturalem (9).

(9) IV Sent. d.33.q.1.a.1 ad $4^{\text {um }}$ : Strictissimo modo accipiendo jus naturale, illa quae ad homines tantum pertinent, etsi sint de dictamine rationis naturalis, non dicuntur esse de jure naturali; sed illa tantum quae naturalis dictat de his quae sunt homini aliisque communia; et sic datur definitio, scilicet, jus naturale est quod natura omnia animalia docuit $-S$. Th., 2., 2. q. 57 a. 3 . c: jus quod dicitur naturale... commune est nobis et aliis animalibus. Ethic. V, lect. XII : Attenditur in homine duplex natura. Una quidem, secundum quod est animal, quae sibi et aliis animalibus est communis. Alia autem natura est hominis, prout scilicet secundum rationem discernit turpe et honestum. Juristae (i. é; os jurisconsultos romanos) autem illud tantum dicunt jus naturale quod consequitur inclinationem naturae communis homini et aliis animalibus, sicut conjunctio maris et feminae, educatio natorum, et alia hujusmodi. Illud autem jus quod consequitur propriam inclinationem naturae humanae, scilicet ut homo est rationale animal, vocant juristae jus gentium, quia eo omnes gentes utuntur, sicut quod pacta sint servanda, et quod legati apud hostes sint tuti, et alia hujusmodi. Utrumque autem horum comprehenditur sub justo naturali, prout hic a Philosopho accipitur. - Optimo comentário de vários textos célebres do Digesto (D. $1.1 .3,4 ; 4 ; 5 ; 6 ; 9$ ) à luz dos princípios aristotélicos' (Et. Nic., V, VII, 1134 b 18 segs.) Não pensamos porém que seja essa a verdadeira exegese dos textos romanos; não se devem entender à luz da moral aristotélica, que nenhuma influência exerceu sôbre Ulpiano nem sôbre GaIo; mas sim à do estoicismo, como deixamos exuberantemente demonstrado na monografia retrocitada e onde se encontrarão provas do que avançamos aqui. Por isso, dissemos que S. Tomás, esforçando-se por adaptar os textos de GaIo e de Ulpialino às idéias aristotélicas (sem dúvida influenciado também por IsIdoro de SevilHA - cf. $S$. Th., 1." 2.8 q. 95. a. 3 e 4) fez uma verdadeira elaboração de idéias suas. Mas como o que agora nos importa é o seu pensamento, nenhum alcance tem a questão de saber se a sua interpretação das doutrinas romanas é ou não exacta. - Pode-se conferir ainda sôbre o pensamento tomista S. Th., 1. 2. q. 95 a. 4 : ad jus gentium pertinent ea quae derivantur ex lege naturae sicut conclusiones ex principiis, ut iustae emptiones, venditiones et alia hujusmodi, sine quibus homines ad 
Mas, - 3) a adequação que a idéia de justiça, e portanto de direito, implica pode fundar-se apenas numa convenção humana, ex condicto; e temos então o direito positivo, ius positivum, iustum legale sive positivum.

O direito positivo pode ser privado ou público, segundo a relação jurídica é entre particulares, ou entre êstes e a comunidade civil. E, como o ius gentium, também o ius positivum se alicerça no ius naturale, mas não do mesmo modo. Porque, diferentemente do ius gentium, deriva do natural, não a modo de conclusão, mas, de determinação, semelhantemente ao que se dá na arte, em que as formas gerais hão-de particularizar-se, para assumirem realidade concreta. Pois, assim como o artífice, para construir uma casa, há-de determinar numa forma particular o plano geral ideado, assim, para legislar eficazmente, não basta o legislador conhecer as normas gerais da lei natural. Os princípios gerais do direito natural - quae in communi sunt de iure naturali, precisam ser determinados por disposições legais - indigent institutione quantum ad eorum determinationem (10). Não podem portanto ser aplicados do mesmo modo a todos, por causa da múltipla variedade das cousas humanas (11). Para a manutenção da ordem jurídica positiva não basta saber-se que o bem deve ser praticado e o mal evitado e que, portanto, todo crime merece uma pena. A sabedoria e o tacto do legislador é que há-de determinar a pena merecida pelo delito - homicídio, furto, roubo. .,

invicem convivere non possunt; quod est de lege naturae, quia homo est naturaliter animal sociale $-I d$., $i b$. ad $1 .{ }^{\text {um }}$ jus gentium derivatur a lege naturali per modum conclusionis.. distinguitur tamen a lege naturali, maxime ab eo quod est omnibus animalibus commune.

(10) S. Th., Suppl. 3.42.2. ad $1^{\text {um }}$ : illa quae in communi sunt de jure naturali indigent institutione quantum ad eorum determinationem, quae diversimode competit secundum diversos status: sicut de jure naturali est quod maleficia puniantur; sed quod talis poena tali culpae apponatur, per determinationem juris positivi fit.

(11) S. Th., 1.2.95.2 ad $3{ }^{\text {um }}$ : principia communia legis naturae non eodem modo applicari possunt omnibus, propter multam varietatem rerum humanarum. Et exinde provenit diversitas legis positivae apud diversos. Cf. Ethic. V lect. XII. 
consideratis omnibus circumstantiis particularibus de tempo, lugar, valor económico, cumplicidade.... e muitas outras peculiaridades impossiveis de se conhecerem anticipadamente. Compreende-se assim como o direito positivo varia de povo para povo e, num mesmo país, com a diversidade de regiões; e que as suas disposições não poderiam ser meras conclusões da lei natural, como as do direito das gentes. Estas últimas proibem ea quae sunt secundum se mala; a legislação positiva veda ea quae possunt esse occasiones malorum (12).

O direito civil é, pois, como diz Garo (D. 1.1.9) quod quisque populus ipse sibi constituit, pelo qual cada Estado determina o que lhe é acomodado (13).

Ora, é facil compreender que, em certo sentido, o ius gentium também é direito positivo e portanto S. Tomás tivesse podido escrever: dividitur ius positivum in ius gen-

(12) In IV Sent; dist. 15, q. 3, art. 1, qla. 4: Praecepta juris naturalis prohibentur ea quae sunt secundum se mala; sed praeceptis juris positivi prohibentur ea quae possunt esse occasiones malorum.

(13) S. Th., 1.2.95.2.c.: a lege naturali dupliciter potest aliquid derivari: uno modo, sicut conclusiones ex principiis (direito das gentes ou natural humano - v. nota anterior); alio modo sicut determinationes quaedam aliquorum communium (é o direito civil). Primus quidem modus similis est ei quo in scientiis, ex principiis conclusiones demonstrativae producuntur. Secundo vero modo simile est quod in artibus formae communes determinantur ad aliquid speciale: sicut artifex formam communem dornus necesse est quod determinet ad hanc vel illam domus figuram. Derivantur ergo quaedam a principiis communibus legis naturae per modum conclusionum: sicut hoc quod est non esse occidendum, ut conclusio quaedam derivari potest ab eo quod est nulli esse faciendum malum. Quaedam per modum determinafionis: sicut lex naturae habet quod ille qui peccat puniatur; sed quod tali poena puniatur, hoc est quaedam determinatio legis naturae. - Texto capital nesta materia e de meridiana clareza. E S. Tomás conclui : ea quae sunt primi modi continentur in lege humana, non tamquan sint solum lege posita; sed habent etiam aliquid vigoris ex lege naturali. Sed ea quae secundi modi, ex sola lege humana vigorem habent - Cf. Id. ib., art. 2 ad $3 .{ }^{. m}$ e art. $4 ; 2.2 .60 .5 ;$ Ethic., V, lect XII. Em III Sent. d. 37 a. 3. sol., S. TomÁs observa, que o direito positivo se reduz ao natural, não absolute, mas, consideratis omnibus circumstantiis particularibus; assim quando se trata, p. ex., de saber qual a sanção eficaz de uma lei penal. 
tium et ius civile (14). Nem isso contradiz o ter identificado o ius gentium com o ius naturale especificamente humano. Porque se de um lado o ius gentium decorre, como vimos, do ius naturale, a modo de conclusão - e só o ser racional é capaz de deduzir conclusões; de outro, não é menos exacto suporem essas conclusões - contractos, propriedade, casamento monogámico, respeito da vida dos próximos etc., - forçosamente o convívio civil. Difere porém do direito natural ${ }_{2}$ - comum aos homens e aos animais; e do civil, resultante sòmente lex humano condicto (15).

O direito civil ou positivo, embora derivado do natural a modo de determinação, como acabamos de ver, não tira daí o seu carácter de obrigatoriedade e a sua sançâo eficaz, senão da vontade do legislador, ex voluntate instituentis. Nisso difere do direito natural; pois, ao passo que êste implica um dever de justiça fundado na razão, secundum regulam rationis, aquele obriga pela lei, secundum regulam legis determinantis, e assim não haure na natureza mesma a sua fôrça obrigatória - praecepta iuris positivi non reducuntur ad naturalia quasi ex ipsa natura vim obligandi habeant. Derivada da natural, é certo que a lei escrita contém o direito natural, mas não o institui - legis scriptura ius quidem naturale continet, sed non institutit; porque não é em virtude da lei positiva que o direito natural é cogente, mas pela natureza - non enim habet robur ex lege. sed ex natura. Ao passo que a lei escrita tanto contém como institui o direito positivo, conferindo-lhe a autorida-

(14) S. Th., 1.2.95.4.c.

(15) S. Th., 1.2.95.4.ad $1^{\text {um }}$ : jus gentium est quidem aliquo modo naturale homini, secundum quod est rationalis: inquantum derivatur a lege naturali per modum conclusionis, quae non est multum remota a principiis; unde de facili hujusmodi homines consenserunt. Distinguitur tamen a lege naturali, maxime ab eo quod est omnibus animalibus commune. - Há visivelmente um esfôrço, da parte de S. Tomás, para conciliar Aristóteles, os jurisconsultos romanos e IsIdoRo DE SEvilha, nesta questão da tripartição do direito. Cf. O. Lotrin, Le Droit Naturel chez saint Thomas d'Aquin et ses prédécesseurs, ed. cit. $3^{\mathrm{me}}$. ptie., ch. I. 
de - ius autem positivum scriptura legis et continet et instituit, dans ei auctoritatis robur (16).

0 direito positivo - civil e das gentes - derivando do natural, supõe como êste um fundamento racional necessário e objetivo: lex est aliquid pertinens ad rationem; ordinatio rationis (17).

Mas, se a ordem jurídica natural apresenta um carácter de relativismo e de contingência, no sentido já explicado, na ordem jurídica positiva, apesar-de racional, essa contingência manifesta-se ainda mais acentuada, por vários motivos.

1. - O legislador, por experimentado que seja, não poderá nunca prever todos os casos: nullius hominis sapientia tanta est ut possit omnes singulares casos excogitare, diz sinaladamente S. Tomás. Por isso visa apenas os casos mais freqüentes, ut in pluribus, os olhos postos no bem comum - ferens intentionem suam ad communem utilitatem (18). Sempre portanto que a aplicação da lei ferir a utilidade geral não deve ser realisada. A lei é para o homem e não o homem para a lei; meio, não fim. Jamais se poderia atribuir a S. Tomás o fiat justitia pereat mundus; nem aceitaria êle nenhuma solução totalitária da ordem civil que, desprezando o valor e a dignidade da pessoa humana, fizesse do direito apenas um instrumento para reduzir o indivíduo à uma peça da grande engrenagem social, absorvendo-o por completo e eliminando-lhe tôda razão de viver (19).

(16) S. Th., 2. 2. 60. 5. c.; Id., 1. 2. 99. 5; Sent. 3. d. 37. q. 1. a. 3 ad $2^{\mathrm{um}} ;$ C. G., 3.123 .

(17) Cf. S. Th., 1.2.90.1.c.; C. G. 3.114: quum lex nihil aliud sit quam quedam ratio et regula operandi, illis solis convenit dari legem qui sui operis rationem cognoscunt. Hoc autem convenit solum rationali creaturae. Soli igitur rationali creaturae fuit conveniens dari legem.

(18) S. Th., 1.2.96.6 ad $3^{\text {am }}$. $O$ artigo tem como título utrum liceat ei qui subditur legi, praeter verba legis agere; e no corpo, S. Tomás dá um exemplo de dispensa da lei, num caso imprevisto.

(19) A ordem jurídica positiva. derivada da natural, tem como limites que não pode ultrapassar, aniquilando-os, os principios fundamentais da nossa natureza racional. Desde o momento em que erige a noção abstracta do Estado em finalidade absoluta de 
O direito positivo se manifesta por aquí sob o império da contingência.

Nem é de admirar a quem não esquecer que a moral, da qual o direito faz parte, tem por objecto material os actos humanos. Ora, êstes, sendo particulares e contingentes, podem variar ao infinito, e portanto não é possível o legislador instituir nenhuma regra permanente e infalível, quae in nullo casu deficeret (20).

Mas ainda que o pudesse, não poderia o legislador, por evitar a confusão, prever todos os casos - propter confusionem vitandam (21). Quantas páginas teria um código de tal natureza? Na contingência se embebem as raizes mesmas da vida humana.

Daí a necessidade de se recorrè à aequitas, chamada pelos gregos epiqueia (epieikeia), que abranda os rigores da justiça, adaptando-se às situações particulares, como a régua lésbia, referida por Aristóteles; corrige as insuficiências do legislador, mas nem por isso se divorcia da justiça, em absoluto, senão só, quando necessário, da legal - justum quod est de lege determinatum. Nem se opõe à severidade da lei, que apenas rejeita por evitar o mal; pois, sequi verba levis in quibus non oportet, vitiosum est (22).

tôda a ordem jurídica, colide com as injunções imprescriptíveis da lei natural e se transforma em regime tiránico e despótico que não pode exigir a livre adesão da nossa consciência. A propósito, e em sentido pouco diferente, poderiamos lembrar o texto do jurisconsulto romano, aduzido por S. Tomás (1. cit.): nulla ratio juris aut aequitatis benignitas patitur, ut quae salubriter pro salute hominum introducuntur, ea nos duriori interpretatione, contra ipsorum commodum, perducamus ad severitatem (D. 1.3.25). Voltaremos amplamente a êste assunto quando, no exame da definição tomista da lei, estudarmos a noção e as exigências do bem comum. Mas o leitor poderá ver desde já, se quizer, DabiN, op. cit., pg. 182 e segs.

(20) S. Th., 2.2.120.1; cf. Id. 1.2.91.3 ad $3^{\text {um }}$;. Ethic., v. 16 .

(21) S. Th., 1.2.96.6 ad $3^{\text {um }}$.

(22) S. Th., 2.2.120.2 ad $1^{\text {um }}$ : epieikeia correspondet proprie justitiae legali. S. Th., 2.2.120.1: epieikeia non deserit iustum simpliciter, sed iustum quod est lege determinatum. Nec etiam opponitur severitati: quae sequitur veritatem legis in quibus oportet; sequi autem verba legis in quibus non oportet vitiosum est. Compreende-se, pois, que considere a equidade - quasi superior regula humanorum actuum (id. ib. a. 2. c.) - Ethic, V. 16: In 
Da insuficiência da lei positiva, para prever e regular tôdas as relações civis entre os homens, não se vá porém concluir, adverte avisadamente S. Tomás, que melhor é ser governado pelo arbitrio do juiz, o iustum animatum de ARIsTóteles, e que as leis são inúteis. Melhor é, apesar-de tudo, o regime da lei, que o de quaisquer homens, por mais capazes e virtuosos que sejam. E justifica por três razóes, a que não se pode negar vigoroso senso da realidade. A primeira é que, embora seja cada caso humano particular. é mais fácil contudo encontrar uns poucos homens prudentes capazes de legislar com tino e sabedoria, do que muitos, que seriam os necessários para julgar bem cada caso concreto. Em segundo lugar, o legislador considera maduramente e com antecedência a matéria da lei; ao passo que um juiz deve decidir sôbre factos particulares, emergentes de súbito. Ora, mais fàcilmente podemos julgar com acêrto depois de aturada reflexão, do que apoiado na consideração de um facto único. E enfim, o legislador, julgando em geral e para o futuro, leva superioridade sôbre o juiz que, devendo dirimir casos actuais, mais fàcilmente se deixa cegar - o que lhe deprava o juizo - do amor, do ódio, da cubiça. Portanto, conclui S. Tomás, como a justiça animada do juiz não se encontra em muitos e é flexível, é necessário, sempre que possível, seja determinado por lei como se deva proceder, deixando pouquísssima margem ao arbítrio humano - et paucissima arbitrio humano committerentur (23). Dos males o menor. Cônscio da contingência das cousas humanas, S. Tomás não resvala na utopia perigosa de muitos reformadores hodiernos.

2. - O legislador defronta freqüentemente com vários meios a escolher, caminhos diversos conducentes ao fim vi-

Lesbia insula sunt lapides duri qui non possunt de facili ferro praescindi ut dirigantur ad omnimodam rectitudinem et ideo aedificatores utuntur ibi regula plumbea. Et sicut illa regula complicata adaptatur ad figuras lapidis, et non manet in eadem dispositione, ita oportet quod sententia judicis adaptetur ad res secundum earum convenientiam.

(23) S. Th., 1.2.95.1 ad $2^{\mathrm{nm}}$. 
sado. Porque nas cousas humanas não há meios determinados para se alcançar um fim; diferençam-se conforme as pessoas e os negócios. $O$ objecto da lei positiva, indeterminado por natureza, é susceptível de determinações divergentes, elegíveis pelo senso jurídico e pela vontade do legislador. Dá-se com êle o que passa com o arquitecto: se quer edificar, há-de empregar madeira, cuja qualidade porém depende da sua livre escolha. Por onde se compreende o dito do jurisconsulto romano, (D. 1.3.20) non omnium quae a maioribus lege statuta sunt ratio reddi potest; muitas instituições do passado são oriundas de circunstâncias nem sempre claras aos olhos do jurista actual. E' a razão por que $b$ costume pode fundar a lei escrita, abrogá-la, derrogá-la, interpretá-la, modificar-lhe o conteúdo. Concorre com a acção do legislador, como fonte importante do direito positivo. Por onde se vê quanto êste difere do natural; pois, ao passo que as suas instituições pode-nas abolir o desuso - por dissuetudinem abolentur, as prescrições do direito natural - ea quae sunt a jure naturali, nada será capaz de as abrogar - nulla dissuetudine aboleri possunt. Assim, em nenhum desuso conseguiria fundar-se a permissão do furto, do adultério, do homicídio (24).

$\mathrm{O}$ direito positivo é, pois, por essência dependente das vicissitudes da vida política. A contingência que, como vimos, já atinge o direito natural, nas suas conseqüências afastadas, penetra por completo a actividade do legislador. Mas nem por isso a ingente tarefa de constituir a ordem jurídica positiva lhe fica entregue aos devaneios do arbí-

(24) S. Th., 2.2.47.15: Ea quae sunt ad finem in rebus humanis non sunt determinata, sed multipliciter diversificantur secundum diversitatem personarum et negotiorum. - Cf. Id. ib., 2.2.57.2 ad $2^{\mathrm{um}}$; Ethic. V, 1. XII. - C. G. 3.97: necessarium est volenti aedificare domum quod quaerat ligna; sed quod quaerat abietina ligna, hoc ex simplici voluntate ipsius dependet, non autem ex ratione domus aedificandae — Cf. Ethic. 1.3; S. Th., 1.2.95.2 ad $4^{\mathrm{um}}$. - Sôbre o costume como fonte da legislação cf. $S$. Th., 1.2.97.3: consuetudo et habet vim legis et legem abolet et est legum interpretatrix. - Quodl. II, a. VI: ea quae sunt de jure positivo per dissuetudinem abolentur; ea vero quae sunt a jure naturali. . nulla dissuetudine aboleri possunt. 
trio. Além de jungido às condições concretas que the cerceiam o agir, há-de sempre empregar a vista no alvo final do bem comum e não perder de sentido as exigências inelutáveis dos princípios sinderéticos. Mas dentro dêsses limites é enorme a sua liberdade de acção, e êle será um eco das transformações políticas, sociais, jurídicas, económicas, elaboradas no seio da comunhão nacional. Assim, frisa S. Tomás, alterando-se o regimen político, muitas leis hão-se de mudar: as próprias à democrácia, govêrno do povo - quae est potestas populi, não se adaptam à oligarquia, govêrno dos ricos - quae est potestas divitum (25).

Mas o mundo de contingências que a involve não tira à lei positiva o atributo necessário de ser a sancionadora e a promulgadora da lei natural. Não que esta seja de todo despida de sanções; mas, $_{2}$ sendo elas de natureza puramente moral, não bastam a coibir as transgressões do maior número. Daí a necessidade da coacção, imposta pelo direito positivo aos que lhe transgridem as injunções; constitui uma sanção exterior e socialmente eficaz. E' o carácter repressivo ou punitivo da lei, que S. Tomás considera ao tratar do fim e dos efeitos dela.

O fim da lei, ensina, é tornar o homem bom; bom é aquele cuja vontade é boa; boa é a vontade que quer o bem e sobretudo o bem por excelência que é o fim. Por onde, quanto mais a vontade o quiser tanto melhor será (26). Ora, como a virtude é a que torna o homem bom, é claro que próprio da lei é levar os homens a serem virtuosos, e ef eito seu torná-los bons (27).

Em princípio poderia ser ordenada a prática de tôdas as virtudies, porque em suma tôdas podem visar o bem co-

(25) S. Th., 1.2.97.1: lex recte mutari potest propter mutationem conditionum hominum quibus secundum diversas eorum conditiones diversa expediunt. - Id., 1.2.104.3 ad $2^{\mathrm{mm}}: \mathrm{Si}$ civitas vel gens ad aliud regimen deveniat, oportet leges mutari; non enim eaedem leges conveniunt in democracia, quae est potestas populi, et in oligarchia, quae est potestas divitum.

(26) Cf. C. G. 3.116; ib., 115,117;S.Th., 1.2 .96 .2 c. e ad $2^{\mathrm{nm}}$; a. 3. c. e ad $3^{\mathrm{um}} ; \mathrm{q} .100 .9$ ad $1^{\mathrm{um}}$ et $2^{\mathrm{um}} ; \mathrm{q} \cdot 107.2$.

(27) S. Th., 1.2.91.1; Sent., III, d. 37. q. 1 ad $2^{\mathrm{um}}$, sol. 1. 
mum, alvo colimado pelo legislador (28). Contudo, não preceitua sôbre todos os actos de tôdas as virtudes, senão só dos ordenados ao bem comum que são, como veremos a seguir, os da justiça (29).

Quando porém S. Tomás assim o ensina, não pretende produza a lei o efeito de tornar realmente cada cidadão virtuoso, porque tal seria o bem particular dêle; e o legislador não visa o bem particular de ninguém. 0 a que deve tender é a uma atmosfera social propícia à vida virtuosa dos membros da comunidade civil; e isso é pròpriamente um bem comum. Por onde, não impõe a ninguém o dever de ser virtuoso; mas o de proceder socialmente como se o fôsse. $\mathrm{E}$ aos que não o são a êsses lhes proíbe, não a prática de todos os vícios; mas sòmente, para procederem como se fôssem virtuosos, a dos que destruiriam, gravemente comprometeriam ou simplesmente perturbariam a ordem jurídica positiva, pela qual deve zelar (30). São, pois, efeitos

(28) Sent. III, d. 33. q. 3. a. 4 sol. 5 ad $3^{\text {um }}$. e $i b$., sol. 6 ad $3^{\mathrm{um}}-$ S. Th., 1.2.96.3. c.; Ethic. V. lect. $2-$ A noção exacta e rigorosa de bem comum, o qual serve de objecto a declamações fáceis e sem nenhuma consistência, havemos de dá-la num estudo subseqüente, ao tratarmos da definição da lei em geral, segundo S. Tomás.

(29) S. Th.. 1.2.96.3. c.

(30) Cf. $S$. Th., 1.2.100.10 ad $2^{\mathrm{um}}$ : intentio legislatoris est de duobus. De uno quidem, ad quod intendit per praeceptum legis inducere; et hoc est virtus. Aliud autem est de quo intendit praeceptum ferre; et hoc est quod ducit vel disponit ad virtutem, scilicet, actus virtutis. Non emin idem est finis praecepti, et id de quo praeceptum datur; sicut neque in aliis rebus idem est finis et quod est ad finem. - C. Id., ib., a. 3 ad $2^{\mathrm{um}}$. - De Regimine Principum, I, 14. - S. Th., 1.2.96.2 c.: lege humana non prohibentur omnia vitia, a quibus virtuosi abstinent, sed solum graviora a quibus possibile est maiorem partem multitudinis abstinere; et praecipue quae sunt in nocumentum aliorum, sine quorum prohibitione societas humana conservari non posset: sicut prohibentur lege humana homicidia et furta et hujusmodi. - Bom comentário ao pensamento tomista encontrará o leitor em LACHANCE - Le concept de droit selon Aristote et Saint Thomas, Paris, Sirey, 1933, pg. 248: Maîtrisant à perfection son sujet, il (S. Tomás) démêle l'object, fin et effet de la loi: l'object est l'acte individuel ordonné; la fin est l'ordre supérieur de l'agir collectif ou le bien commun en acte; l'effet est la vertu ou le bien commum dans sa racine. Et le droit s'insère précisément dans l'object de la loi (id de quo praeceptum datur), c'est-à-dire dans l'acte de l'individu, afin de l'adapter soit à ses semblables, soit à l'ordre superieur constituant le bien 
da lei positiva: imperare, ordenar a prática de certos actos - os genèricamente bons; prohibere, proibir a de outros os genèricamente maus. Os genèricamente indiferentes ela os permite, permittere. E como para se fazer obedecer comina o legislador penas aos transgressores ,o quarto ef eito da lei é punir, punire (31). E' a coacção a que mais acima aludimos.

Ora, a lei coage pelo temor da pena: coactio legis est per metum poenae; id per quod inducit lex ad hoc quod sibi oboediatur est timor poenae. Porque a protérvia e o natural revel de muitos torna-os insubmissos e violadores da ordem jurídica; não obedecendo voluntariamente à lei, esta, coagindo-os pelo temor do castigo, cogens metu poenae. constrange-os ao jugo e a colaborar na realização do bem comum. Tal é a função disciplinar da lei, disciplina legum (32).

Dessa disciplina ou aprendizagem deflui o efeito educativo da lei positiva, a redundar no próprio punido que,

commum. (Grifos nossos). Do mesmo autor - L'humanisme politique de Saint Thomas, Paris, Sirey, 1939, II, 486. - Mélanges thomistes, Le Saulchoir, Kain (Bélgica), 1923, pg. 348, art. de E. Hugueny intitulado - L'État et l'individu. Entre outras cousas nota o seguinte: la vie vertueuse de la multitude n'est pas une vie vertueuse au sens complet du mot, mais une orientation vertueuse des forces sociales organisées de telle façon, qu'elles provoquent, facilitent et protègent le plein épanouissement de la vie vertueuse des individus.

(31) S. Th., 1.2.92.2. c.; id. ibid. 90.3 ad $2^{\text {um }}$. No artigo anterior S. Tomás é visivelmente influenciado pelo famoso texto de Modestino (D. 1.3.7) - legis virtus haec est: imperare, vetare, permittere, punire; através de IsIdoRo dE SEVILHA, como se conclui do sed contra.

(32) S. Th., 1.2.100.9 c.: praeceptum legis habet vim coactivam. Illud ergo directe cadit sub praecepto legis, ad quod lex cogit. Coactio autem legis est per metum poenae. Nam illud proprie cadit sub praecepto legis, pro quo poena legis infligitur Id. ib. 92.2.c. - Ethic., $\mathrm{X}$, 1. 14: multi homines non possunt per sermones provocari ad bonitatem... sed magis coercentur timore poenarum. Non enim recedunt a pravis operibus propter eorum turpitudinem, sed propter poenas quas timent. - Id. ib.: multi enim sunt, qui magis obediunt necessitati, idest coactioni, quam sermoni. Et magis obediunt jacturae, idest, damno, quod incurrunt pro poenis, quam bono honesto. 
pelo costume, será levado a praticar de grado o que antes só o fazia pela manudução coactiva (33).

Como tôda disciplina, a das leis se perfaz lenta e demoradamente: lex humana, pondera S. Tomás com profundo bom senso, intendit homines inducere ad virtutem, non subito, sed gradatim. Êle não ignora ser a lei positiva feita para uma multidão composta, na sua maior parte, de homens de virtude imperfeita. Por isso mesmo, como vimos, não coibe todos os vícios, senão apenas os mais graves, como o homicídio, o furto e semelhantes; mínimo necessário à subsistência do bem comum, e de que o grande número é susceptível. A educação social operada pela lei não escapa à condição geral das cousas humanas: - non subito, sed gradatim; $a b$ imperfecto ad perfectum (34). Ao século XVIII, e a Rousseau em particular, estava reservado ensinar o oposto a essas verdades confirmadas pela experiência quotidiana, proclamando o absurdo dogma da bondade primitiva do homem, inocente vítima da sociedade, que o corrompeu...

S. Tomás pode, pois, dizer com verdade: duas cousas a lei é por essência - regra dos actos humanos e dotada de fôrça coactiva (lex de sui ratione duo habet: primo quidem, quod est regula humanorum actuum; secundo, quod habet vim coactivam) (35). O direito positivo é, a esta luz, a verdadeira sanção temporal do direito natural; e Dabin

(33) S. Th., 1.2.95.1.c.: quia inveniuntur quidam protervi et ad vitia proni, qui verbis de facili moveri non possunt, necessarium fuit quod per vim vel metum cohiberentur a malo, ut saltem sic malefacere desistentes, et aliis quietam vitam redderent, et ipsi tandem, per huiusmodi assuetudinem, ad hoc perducerentur quod voluntarie facerent, quae prius metu implebant, ret sic fierent virtuosi.

(34) Cf. S. Theol. 1.2.92.1 ad $2^{\text {um }}$; id., ib.. 96.2.c. e ad $2^{\text {um }}$ : lex humana intendit homines inducere ad virtutem. non subito, sed gradatim. Et ideo non statim multitudini imperfectorum imponit ea quae sunt iam virtuosorum, ut scilicet ab omnibus malis abstineant; alioquin imperfecti hujusmodi praecepta ferre non calentes, in deteriora mala proprumperent. - No mesmo sentido Quodlibet. II. a. 10. ad $2^{\mathrm{um}}$. Cf. em Mélanges Thomistes, Le Saulchoir, Kain (Bélgica), 1923, pg. 356 art. de E. HuguenY.

(35) S. Th., 1.2.96.5. c. 
(op. cit. pg. 56) tem razão em afirmar, que la contrainte publique est de l'essience du droit; du droit juridique, numa terminologia muito pouco feliz para designar o direito positivo.

E' mister porém notarmos que da afirmação de S. Tomás - a lei positiva é por essência dotada de fôrça coactiva, não se deve concluir pense êle ser a coacção da essência do direito em geral. Basta atender à sua concepção do direito natural, já exposta, para não lhe atribuir tal absurda conseqüência (36).

(36) A doutrina corrente, de que a fôrca coerciva do Estado, a serviço do direito, faz parte da essência dêste divulgou-se por influencia de KANT, embora antes já ensinada por PUFENDORFF (16321694). Nos seus Principios fundamentais metafísicos da doutrina do direito (Metaphysische Anfangsgründe der Rechtslehre), ensina: Das stricte Recht kann auch als die Möglichkeit eines mit jedermanns Freiheit nach allgemeinen Gesetzen zusammenstimmenden, durchängigen, wechselseitigen Zwanges vorgestellt werden. . man kann den Begriff des Rechts in der Möglichkeit der Verknüpfung des allgemeinen, wechselseitigen Zwanges mit jedermanns Freiheit unmittelbar zetzen. Recht und Befugnis zu zwingen bedeuten. also einerlei (Einleitung, § E; cf. § D. - grifo nosso) Ou em português: "O direito estrito pode também ser representado como a possibilidade de uma coação geral e recíproca, concordando, segundo leis universais, com a liberdade de cada um.. Podemos fazer imediatamente consistir o conceito de direito na possibilidade da concordância de uma coacção geral e recíproca com a liberdade de cada um... Direito e faculdade de coagir significam portanio o mesmo". E' verdade que logo adiante (Anhang zur Einl. in die. Rechtslehre) KaNT acrescenta: "Todo direito, no sentido estrito (ius strictum), é acompanhado da faculdade de coagir. Mas podemos ainda conceber um direito em sentido lato (ius latum), em que a faculdade de coagir não pode ser determinada por nenhuma lei. (Mit jedem Recht in enger Bedeutung — ius, strictum — ist die Befugnis zu zwingen verbunden. Aber man denkt sich noch ein Recht im weiteren Sinne (ius latum), wo die Befugnis zu zwingen durch kein Gesetz bestimmt werden kann). Este porém é a aequitas; não é o direito em sentido próprio. O seu pensamento é muito claro e incontroverso. Mas é absolutamente erróneo, como uma reflexão atenta fàcilmente o demonstra. Não está nos limites do nosso estudo fazê-lo; mas o leitor interessado poderá ver uma irrespondível refutação dessa perigosa doutrina na excelente obra já citada de Cathrein - Recht, Naturrecht und positives Recht, Freiburg, Herder, 1909, pg. 94 e segs. - Entre muitos outros, IHERING, fazendo-se eco dessa teoria, compara: ein Rechtssatz ohne Rechtszwang ist ein Widerspruch in sich selbst, ein Feuer, das nicht: brennt, das Licht, das nicht leuchtet. (Der Zweck im Recht, Leipzig, Breitkopt u. Härtel, 1893, I ${ }^{\text {er. }}$ Bd., S. 322). Compreende-se que IHERING assim o pense,. êle que ousa afirmar êste absurdo: der Staat 
Duas porém são as espécies de coacção: a externa, a que repugna a vontade e elimina o mérito, e tais são as penalidades cominadas pelo legislador aos infractores da lei; e a interna, i. é, a defluente das exigências do fim voluntàriamente proposto, e que se coaduna com o mérito (37).

$O$ direito positivo dispõe de ambas: aquela para os maus cidadãos, esta para os bons. Os últimos, melhor dirigidos por advertências, de bom grado acatadas, do que pela coerção, não estão, a bem dizer, sujeitos à lei, non sunt sub lege; mas só os maus, sed soli mali. Pois, o coacto e o violento contrariam a vontade. Ora, a vontade dos bons, em oposição à rebeldia dos maus, já é de si submissa (38).

Cumpre porém não esquecer que ao legislador não é lícito cominar penas senão por actos humanos externos, respeitantes ao bem comum, e que, portanto, implicam a idéia de justiça - os únicos a lhe cairem sob a alçada (39).

die alleinige Quelle des Rechts ist (id. ib., 320). - Entre nós o Snr. PeDro Lessa incide no mesmo êrro quando, na sua pretendida definição do direito, defeituosa a tantos respeitos, afirma:.. "e que é necessário sejam garantidas pela fôrça coercitiva do Estado" (Estudos de Philosophia do Direito, Rio de Janeiro, 1912, pg. 62). Entretanto, muitos dos que assim pensam ficariam estarrecidos (ilogicamente!) diante de um truculento despotismo de Estado!...

(37), Cf. S. Th., 2.2.58.3. ad $2^{\mathrm{um}}$. - LACHANCE, L'idée du droit, pg. 310 .

(38) Cf. S. Th., 1.2.95.1. ad $1^{\text {um }}$; id. ib., 96.5.c.: Alio vero modo dicitur aliquis subjectus legi sicut coactum cogenti. Et hoc modo homines virtuosi et justi non subduntur legi; sed soli mali. Quod enim est coactum et violentum est contrarium voluntati. Voluntas autem bonorum consonat legi, a qua malorum voluntas discordat. Et ideo, secundum hoc, boni non sunt sub lege; sed solum mali. - Prova clara que, para S. Tomás, a coacção. não é da essência do direito; pois, se o fôsse, chegaríamos à conclusão absurda que os bons, a melhor parte da sociedade civil, não têem nenhum direito porque, dobrando-se docilmente ao jugo da lei, tornam de todo inútil o recurso à coerção penal!...

(39) Cf. Ethic., V. 1. 2. - S. Th., 1.2.100. 9. c.: Poena legis non infligitur nisi pro illis de quibus legislator potest judicare, quia ex judicio lex punit; homo autem qui est legis lator humanae, non habet judicare nisi de exterioribus actibus, quia homines vident ea quae parent. - Id. ib., 98. 1. c.: Legis humanae finis est temporalis tranquillitas civitatis; ad quem finem pervenit lex, cohibendo exteriores actus, quantum ad illa mala quae possunt perturbare pacificum statum civitatis. - Id. $i b ., 96$. 3: Non de omnibus actibus omnium virtutum lex humana praecipit, sed solum de his qui ordinabiles sunt ad bonum commune. - Id. ib., 100. 2: lex humana non proponit praecepta nisi de actibus justitiae. 
Mas S. Tomás daí não conclui, anticipando o êrro de Tomásio, de Kant, Fichte e inúmeros outros (40), serem os actos externos os que essencialmente diferençam o direito, da moral. Já aduzimos muitos lugares das suas obras por onde o leitor poderá discernir-lhe o pensamento no atinente às relações entre o direito e a moral. Todavia, como esta matéria anda de ordinário envolta na caligem de tamanhas confusões, não serão demasiado esclarecimentos a mais.

$\mathrm{O}$ direito, já o vimos, é o objecto da justiça; ius est objectum justitiae (41). E esta, em sentido próprio e estrito, é, segundo a define UlPIANo, constans et perpetua voluntas ius suum cuique tribuendi. Ora, sendo o objecto da justiça, o direito - tanto o natural, como o positivo, com que agora nos ocupamos, forçosamente se inclui na ordem moral, por ser a justiça uma virtude moral. Mas, não se identifica com a moral na extensão da sua aplicabilidade. porque respeita só a idéia de meu e teu: suum cuique (42).

(40) Cristiano Tomásio (1655-1728), na sua obra Fundamenta Juris naturae et gentium ex sensu communi deducta, (1705), considera três princípios: o justum, o decorum e o honestum. No primeiro se funda o direito natural, cujo fim é garantir a paz da ordem externa; no segundo, a pol̆́tica cujo fim é realisar mediante a benevolência as exigências dessa paz; no terceiro, a ética, que visa alcançar a paz interna da alma. E' muito nítida a diferença, que implica, entre direito e moral. Kant define o direito: Inbegriff der Bedingungen, unter denen die Willkür des einen mit der andern nach einem lallgemeimen Gesetz der Freiheit zusammen vereinigt werden kann. (Op. cit., ib., B) o principio geral do direito assim o concebe: Eine jede Handlung ist recht, die oder nach deren Maxime die Freiheit der Willkür eines jeden mit jedenmanns Freiheit nach einem allgemeinen Gesetze zusammen bestehen kann. (id. ib.) C). Portanto só visa a ordem externa, o que $\mathrm{K}$. expressament o diz um pouco antes, na Einleit., B. 1.0 - Concepção semelhante se encontra em Fichte (Grundlage des Naturrechts, S. W., Leipzig, Meyer, III, 52).

(41) Cf. S. Th., 2.2.57.1, onde estão as provas desse assêrto.

(42) S. Tomís assim define o seu, de cada um: dicitur esse suum alicuius, quod ad ipsum ordinatur. $S$. Th., 1.21.1. ad $3^{\text {um }}$. E ainda $S$. Th., 2.2.58.11: dicitur esse suum unicuique personae, quod ei secundum proportionis aequalitatem debetur. Concepção semelhante é a de Kant: Das rechtliche mein (meum juris) ist dasjenige, womit ich so verbunden bin, dass der Gebrauch, den ein anderer ohne meine Einwilligung von ihm machen möchte, mich lädieren wünde! (Op. cit. $\mathrm{I}^{\mathrm{te}}$. Abschn. I, 1.). 
Portanto, a ordem jurídica é apenas a ordem da justiça; ou, se preferirmos, a ordem moral da justiça. Tudo quanto não concerne à justiça não concerne ao direito; ao inverso, tudo o concernente ao direito, seja sob que ângulo for, concerne necessáriamente à justiça. Conceitos de justiça e direito, assim entendidos, coincidem totalmente; nenhuma relação de direito - natural ou positivo - é exclusiva da idéia de justiça, ou a ela estranha.

Ora, a justiça, supondo essencialmente relações com outrem - semper est ad alterum, pois ninguém pode se obrigar para consigo mesmo; e tendo por função realisar uma igualdade, dando a cada um o seu, implica por fôrça actos externos, os únicos a serem considerados pelo legislador (43). Neste sentido é exacto dizer-se que o direito é a parte da moral, cujo objecto são êsses actos. Mas não é essa uma característica essencial, senão apenas acidental, do direito. Ora, como nada se define pelo acidental, senão pelo essencial, querendo distinguir o direito, da moral, com tal critério acabaríamos confundindo o domínio de ambos. Pois, muitos actos externos, relações de homem para homem, escapam à alçada da justiça e do direito, embora não à do moral. Assim, pecaria contra a moral, não porém contra o direito positivo, aquele que, p. ex., praticasse actos de ingratidão para com quem tivesse o dever do reconhecimento.

Sendo, pois, o direito, ius, o objeto de justiça, iustitia, há tríplice relação jurídica, que ao legislador cumpre considerar, fundada na tríplice relação de justiça: a justiça comutativa, a legal ou social e a distributiva (44).

(43) S. Th., 2.2.58.2 - V. em LAchance, op. cit., ótima explanação do assunto: pgs. 217-222; pgs. 256-288, e os inúmeros textos aí aduzidos. A diceologia de S. Tomás é fundada, como é fácil verificar, na de Aristóteles; e desta disse com admiração BerolzheiMER: Die Dikäologie des Aristoteles ist seine unsterbliche Meistertat (System der Rechts - u. Wirtschaftsphilosophie, II, 93, apud Cathrein, op. cit., 47).

(44) ' $E^{\prime}$ a clássica e perfeita divisão da justiça formulada por Aristóteles em Ethic. Nic., 5.3. 
A justiça comutativa é a justiça no sentido rigoroso e próprio, tal como Ulpiano a define; supõe relação de igualdade entre particulares. A justiça legal, também denominada comum, geral ou, modernamente, social, é a reguladora das relações entre os membros da comunidade civil e o Estado, expressão política dessa comunidade. Chama-se legal porque a lei positiva determina os encargos de cada cidadão, em vista do bem comum. A justiça distributiva, ao contrário, rege as relaçóes entre a comunidade, ou o Estado por ela, e cada um dos seus membros; confere o direito a certas vantagens, como retribuição do Estado pelos encargos impostos em nome da justiça legal; é uma distribuição de recompensas.

Ora, nem na justiça distributiva nem na legal a relação é de estrita igualdade, como na comutativa. Realizam pois a justiça, e portanto o direito, num sentido derivado e constituem o direito público; ao passo que a justiça comutativa constitui o direito privado, o direito no sentido próprio e rigoroso: nomen ius prius impositum est ad significandum rem iustam (45).

Seja porém qual for o sentido em que consideremos o direito, e portanto a justiça, de que êle é o objecto, a idéia de direito supõe a de lei : a lei é a causa do direito. E' o modernamente chamado direito objectivo, norma agendi, em oposição ao direito subjectivo, facultas agendi, derivada da norma ou da lei (46).

(45) Cf. S. Th., 2.2.57.1 ad $1^{\text {um }}$ - C Cathrein, op. cit., pgs.

(46) A terminologia que distingue a lei, norma agendi, do direito, facultas agendi, embora corrente, é susceptível de crítica. Pois, como muito bem adverte Cathrein (op. cit. 60), já o direito no sentido de seu ("isto é meu", "é meu direito") é um verdadeiro direito objectivo. Além disso, essa divisão, puramente analógica, leva à confusão entre direito e moral; os juristas modernos entretanto, tão ciosos de os manter separados, chegam até, como KANT e muitos outros, a estabelecer compartimentos estanques entre aquele e esta! Pois, na verdade, quem não compreende que facultas agendi, expressão de todo indeterminada, pode se aplicar tanto a actos jurídicos como a actos morais! $\mathrm{E}$ a evasiva, que a refere apenas a actos de justiça, se enreda num círculo: especifica o direito pela justiça e a justiça peto direito!... (Cf. LahancE, op. cit. 410). Quanto mais preciso e luminoso é o pensamento de S. Tomás: o 
Embora, pois, a lei, pròpriamente falando, não seja o direito - lex non est ipsum jus, proprie loquendo, podemos contudo dizer que encerra uma certa noção dêle, aliqualis ratio juris; é o direito, embora em acepção secundária e menos própria, pois o estatui, lex statuit ius (47).

O direito mantém assim dupla relação: com a justiça, da qual é o objecto; e com a lei da qual é o efeito. A fórmula seguinte exprime perfeitamente o pensamento de $S$. Tomás: a lei causa o direito por intermédio da justiça (48).

E somos assim naturalmente levados à questão da essência da lei, tão profundamente versada por S. Tomás. Mas

direito, objecto da justiça, supõe a lei que o causa - sicut se habent artificiata ad artem, ita se habent opera justa ad legem cui concordant (S. Th., 1.21.2.c.). Por isso, mui advertidamente, S. Tomás nunca emprega a palavra ius, direito, no chamado sentido subjectivo, para designar facultas; mas prefere os termos licitum (de lex), potestas. Por ex., referindo-se à propriedade privada: unum est potestas procurandi et dispensandi. Et, quantum ad hoc, licitum est quod homo propria possideat $(S . T h ., 2.2 .66 .2-c f . i b .64 .7$; Sent. 3. d. 37. q. 1. a. 4 etc.). Porque bem sabe ser o sentido objectivo o primário e próprio do direito; e nem mesmo pensa em considerar como derivado, o sentido subjectivo, quando escreve (S. Th., 1.2.57. ad $1^{\mathrm{um}}$ ): hoc nomen ius primo impositum est ad significandam ipsam rem iustam; postmodum.. ad artem, qua cognoscitur quid sit justum; et ulterius ad significandum locus in quo ius reditur... et ulterius, dicitur etiam ius quod reditur ab eo ad cuius officium pertinet iustitiam facere, licet etiam id quod decernit sit iniquum. - Estas últimas palavras, como todo o contexto, mostram que S. Tomás tinha em mente o frgm. de Paulo no Digesto (1.1.11); e seria a ocasião azada a considerar também o direito como facultas... (Cf. LotTin, Le Droit Naturel chez Saint Thomas d'Aquin et ses predécésseurs, ed. cit., 97. n. 1). Tem, pois, toda razão LACHANCE quando afirma (op. cit. 414) : S. Thomas n'a donné nulle part cette division $d u$ droit en objectif et subjectif comme fondamentale, et pour, cause. Car pour peu que l'on réflechisse, l'on voit que cette division "per prius et posterius" est plutôt une "opposition relative" qu'une division. Essa terminologia imprópria foi posta em circulação no sec. XVI, por Suarez, que no seu justamente famoso tratado $D e^{d}$ legibus escreve (1. I. cap. 2. n. 4): Et juxta posteriorem et strictam juris significationem solet proprie jus vocari facultas quaedam moralis, quam unusquisque habet circa rem suam, vel ad rem sibi debitam. Quanto às razões históricas explicativas dessa concepção, e à sua influência, v. LAcHANCE, op. cit., pgs. 401 e segs., onde também se lerá (até pg. 417) ótima crítica da mesma.

(47) $S$. Th., 1.2.57.1 ad $2^{\text {um }}$; Id., 2.2.80.a.u.c.: debitum legale est ad quod reddendum aliquis lege adstringitur. - Cf. LAcHaNCE, op. cit. pg. 227.

(48) Lachance, op. cit. pg. 220. 
antes queremos fazer triplice aplicação da doutrina exposta: ao direito de propriedade, ao casamento monogámico e à escravidão. Os princípios tomistas ficarão dêsse modo porventura mais em evidếncia.

a) A propriedade privada. - A leitura menos atenta de alguns lugares isolados da obra de S. Tomás poderia conduzir à conclusão, que êle não admite a propriedade privada dos bens materiais como instituição de direito natural. Mas um exame aprofundado levará ao contrário.

Em síntese, a questão pode resolver-se do modo seguinte. Consideradas as cousas materiais em si mesmas e absolutamente, na própria essência delas, não sendo criação nem feitura do homem e, portanto, não mantendo com êle qualquer adequação natural, nenhuma razão há de pertencerem antes a um que a outro. Que direito assiste a um, com exclusão de outro, de se apropriar de um campo e dizer: é meu?. Debaixo desta razão, pois, não podemos considerar de direito natural a propriedade privada dos bens dêste mundo: secundum ius naturale non est distinctio possessionum. Todos têem, indistintamente, direito ao uso dêles; a comunidade dos bens é a postulada pelo direito natural. Aquele, pois, que, em iminente perigo de vida, se apoderasse manifesta ou ocultamente de cousas alheias, como supremo e único meio de salvação, não cometeria furto nem roubo - nec hoc proprie habet rationem furti vel rapinae. A necessidade constitui nosso o de que nos apropriamos para manutenção da vida. E nisso o homem procede como qual quer animal irracional. Ora, é precisamente a comunidade de natureza, que o assimila ao bruto, o fundamento do direito natural, - quod natura omnia animalia docuit. E S. Tomás conclui: quanto ao uso das cousas exteriores o homem não nas deve possuir como próprias, mas, como. comuns: non debet homo habere res exteriores ut proprias, sed ut communes (49).

(49) Tudo o que fica afirmado se funda nos lugares seguintes, conforme a ordem da exposição supra: $S$. Th., 2.2.66.1.c.: 2.2.57. 3.c.; 2.2.66.2.c. e ad $1^{\text {um }}$., ad $2^{\text {um }}$; Polit. II lect 4 e 6; S., Th., 2.2.66.7.c. e ad $1^{\text {um }}$; 2.2.66.2.c. 
Mas, adverte, a comunidade de bens o direito natural. a institui antes de modo negativo, que positivamente: não dita que tudo deva ser possuido em comum e nada em particular; mas, não introduzindo discriminações de propriedades, deixa-as ao uso comum. A comunidade de bens é natural, no mesmo sentido em que dizemos ser o homem nu, por natureza, porque esta não instituíu o vestuário, invento da civilisação e da arte. É natural ainda, como o é a liberđade: a natureza não consagrou a escravidão, contrária à liberdade, nem a propriedade particular, contrária à comunidade de bens.

A propriedade privada não é, assim, contrária ao direito natural - non est contra ius naturale; mas, não tendo sido instituida por êle, só o pode ter sido pelo direito positivo - secundum humanum condictum, quod pertinet ad ius positivum. Só êste justifica o poder de aquizição e de disposição, que o homem tem sôbre as cousas materiais. Pois, considerado um campo em si mesmo, não há razão para ser. propriedade de um, com exclusão de outro; mas, quanto à oportunidade de cultivá-lo e ao seu uso pacífico, haverá uma certa razão proporcional de pertencer à êste e não àquele - secundum hoc habet quamdam commensurationem ad hoc quod sit unius et non alterius. E é função do direito positivo - per adinventionem rationis humanae estabelecer essa commensuratio, verdadeiro acréscimo feitoao direito natural - iuri naturali superadditur (50). Ilustração ao que já dissemos, quando, tratando do direito. natural ,explicámos como S. ToMás, com admirável senso da realidade ,admite-lhe variações já por subtração, já por acréscimo. Êste último é comparável, em relação à lei natural, ao vestuário, em relação à nudez primitiva.

Quando porém S. Tomás se refere à propriedade pri-. vada como instituição da convenção humana - humanum condictum, i.é. do direito positivo, não é o direito civil, no sentido do direito romano, que tem em vista, mas o direito.

(50) S. Th., 1.2.94.5. ad $3^{\text {um }}$; 2.2.66.2.c.; 2.2.57.3.c. 
das gentes, ius gentium, na acepção de GaIo. Pois, conforme já elucidámos, considera o ius gentium e o ius civile subdivisões do ius positivum (51).

Ora, o ius gentium se diferença do ius naturale, segundo vimos, por ser êste, na expressão do jurisconsulto romano, aceita por S. Tomás, omnibus animalibus commune; e aquele solis hominibus inter se. O ius gentium é, como também já o sabemos, o direito natural especificamente humano: quod naturalis ratio inter omnes homines constituit, diz Garo.

Ora, para S. Tomás o direito das gentes, conforme deixámos explanado, deriva por umas quasi conclusões, do do direito natural. Isto é, por via de comparação, cousa de que o animal é incapaz. Por onde, a propriedade privada, ius procurandi et dispensandi, e não a comunidade de bens, é que é de direito positivo, embora imediatamente, de direito natural. Nem há mister qualquer especial instituição do legislador, non indiget aliqua speciale institutione, porque as institurções do direito das gentes, ea quae sunt iuris gentium, é a própria razão natural que as dita - ipsa naturalis ratio ea instituit (52). Lesam, portanto, um direito natural humano tôdas as legislaçóes que suprimem a propriedade privada.

Mas isto não impede consideremos as cousas materiais como de certo modo, de uso comum - quod fiant communes aliquo modo quantum ad usum. O exemplo da extrema necessidade, supra aduzido, bem o fará compreender. Determinar outros casos semelhantes pertence à providência do bom legislador - hoc pertinet ad providentiam boni legislatoris (53).

(51) S. Th., 1.2.95.4.c.: dividitur ius positivum in ius gen. tium et ius civile, secundum duos modos quibus aliquid derivatur a lege naturae.

(52) S. Th., 2. 2.57.3 ad $3^{\mathrm{um}}$.

(53) Cf. S. Th., III. ${ }^{\circ}$ Suppl. 65.1. ad $4^{\text {um }}$. Polit., 4 - Cf. sôbre tôda esta matéria: LotTrn, Loi morale etc., ed. cit. pg. 272 ; id., Le Droit Naturel etc., ed. cit., pg. 89 n. 4; Valensin, op. cit., II, pgs. 45, 57; Cathrein, Moralphilosophie, ed. cit., II, pg. 325. Id., Phil. Moralis, ed. cit., pg. 315; Carlyle, op. cit., V, pg. 17 e segs. Deplorge, op. cit., 355-8. Adverte Derlorge muito a propósito que 
b) A organização da família. - O matrimónio dará lugar a uma segunda aplicação da teoria tomista do direito natural. Duas questões relativas a êle se impõem ao nosso exame: se é de direito natural; se deve ser monogámico, poliândrico ou poliginico.

O matrimónio é, antes de tudo, de direito natural, strictissimo modo, no sentido de UlPIANo - quod omnia animalia docuit (54). Mas além disso, no sentido pleno da expressão, é de direito natural humano, pois, se o homem é um animal político, mais verdadeiramente ainda poderiamos denominá-lo animal conjugal (55). A sociedade doméstica é a primeira onde se encontra ,e é por isso anterior à sociedade civil, e mais necessária que esta (56).

Mas como, no sentido humano, lex naturalis est aliquid per rationem constitutum (57), e o homem tem uma inclinação natural a proceder racionalmente - naturalis inclinatio cuilibet homini ad hoc quod agat secundum rationem (58), conforme já vimos, busca a sociedade conjugal, não sòmente por um acto instintivo, mas ainda reflectido. $\mathbf{E}$ a

na sua preferência pela propriedade privada. ao comunismo dos bens, ce qui est essentiel à retenir, c'est d'abord que saint THomas ne se prononce en faveur d'un régime économique qu'à raison de ses avantages sociaux, et c'est ensuite qu'il demande la preuve de ces avantages à la méthode d'observation (grifo meu). - Boa refutação do comunismo de bens, em Politic., II lect. 2 , 3 ; lect. 4.

(54) Polit. I, 1: Invenitur aliquid in homine quod est commune ei et aliis et huius est generare. Hoc competit ei secundum rationem communem sibi et animalibus et etiam plantis. $-S$. Th., III $^{\text {ae }}$ Suppl., 67.1: Conjunctio maris et feminae dicitur esse de iure naturali, quia natura hoc animalia docuit. - E' a segunda das inclinações naturais ao homem, a qué visa a conservação da espécie: Secundo inest homini inclinatio ad aliqua magis specialia secundum naturam, in qua communicat cum caeteris animalibus; et secundum hoc dicuntur ea esse de lege naturali quae natura omnia animalia doculit, ut est comixtio maris et feminae et educatio liberorum et similia. $-S$. Th., 1.2.94.2 - Cf. ainda: Id. $3^{\text {ae }}$. sup. 65.1;Ethic. VIII, 12; Sent. IV, d. 33.9.1.a.1.

(55) Ethic., VIII, 12: Homo est animal naturaliter politicum; et multo magis est in natura hominis quod sit animal conjugale.

(56) Id. ib.: societas domestica est prior quam societas civilis. Est etiam magis necessaria quia societas domestica ordinatur ad actus necessarios vitae, scilicet generationem et nutritionem.

(57) S. Th., 1.2.94.1.

(58) Id. ib., 94.3. 
esta luz o matrimónio é de direito natural humano: et hoc modo matrimonium est naturale quia ratio naturalis ad ipsum inclinat (59). Inclinação especifica da natureza humana, distinta assim da primeira, puramente animal e genérica $(60)$.

Tem duplo fim: um principal - a procriação e a educação, o bem da prole, educatio, bonum prolis; outro secundário - a sociedade conjugal, viri ad mulierem associatio (61). Procriação, educação dos filhos, sociedade conjugal - tal a tríplice finalidade imposta pela natureza ao matrimônio. A primeira, totalmente comum ao homem e aos animais; a segunda, enquanto criação, também participa dessa comunidade; mas já como educação é, com a terceira, especificamente humana (62).

Constituido, deve ser monogámico ou poligámico? A solução da segunda questão nos levará à da primeira.

A poligamia pode apresentar-se como poliandria ou como poliginia. Colidem com o direito natural?

Quanto à poliginia, pluralitas uxorum, nem totalmente suprime, nem mesmo de certo modo impede o fim primário do matrimónio; pois, tanto a procriação como a educação dos filhos ficam asseguradas. Mas, embora não elimine de todo, dificulta a consecução do fim secundário; pois, fácil é

(59) Id. $3^{\text {ae }}$. sup. 41.1.c.

(60) Id. ib., ad $1^{\mathrm{um}}$.

(61) Id. ib. c. - Ethic. VIII; 12: amicitia conjugalis in hominibus non solum est naturalis sicut in aliis animalibus, utpote ordinata ad opus naturae quod est generatio, sed etiam est economica, utpote ordinata ad sufficientiam vitae domesticae. $-S$. Th., $3^{\mathrm{a} \theta}$. sup. 41.1.c.: matrimonium est naturale. primo quantum ad principalem eius finem, qui est bonum prolis. Non enim intendit natura solum generationem prolis, sed etiam traductionem et promotionem usque ad perfectum statum hominis inquantum est homo, qui est virtutis status. . secundo, quantum ad secundarium finem matrimonii, qui est mutuum obsequium sibi a conjugibus in rebus domesticais impensis. - Cf. Id., ib., 61.1 e 65.1 ; $I b$., 49.21; In prole non solum intelligitur procreatio prolis, sed etiam educatio ipsius., ib. $59.2-I d$. 1.98.1.

(62) S. Th., $3^{\text {ae }}$. sup. 65.1: Matrimonium habet pro fine secundario in hominibus solis communicationem operum quae sunt necessaria in vita. - Cf. Ethic. VIII, 12. 
compreender quão gravemente compromete a existência da sociedade conjugal.

Por onde, não colide, de modo absoluto, com as exigências da lei natural. Isto é, a poliginia não contraria os preceitos primários, prima praecepta, da lei natural ou direito natural; mas encontra os preceitos secundários, praecepta secunda, que são umas quási conclusões derivadas dos primeiros. Mas ,como os actos humanos, e portanto o direito, nos seus preceitos secundarios, são contingentes, variam conforme as diversas condições de pessoas, tempos e.outras circunstâncias, essas quási conclusões não têem eficácia sempre, mas na maior parte dos casos - non procedunt ut semper efficaciam habentes, sed in majori parte. Porque assim é a sciência moral - talis est enim tota materia moralis. A poliginia poderia, pois, em casos excepcionais, ser permitida por direito divino, do que as Escrituras nos oferecem exemplos. Pois, sendo o fim primário do casamento a multiplicação da prole, a êsse fica subordinado o secundário - a sociedade conjugal. Mas nada disto se daria, se a poliginia colidisse com os preceitos primários da lei natural.

Ora, tal é o caso da poliandria, contrária aos principios primários do direito natural. Porque, de um lado, compromete gravemente um dos fins primários do casamento bonum prolis, embora não suprima totalmente a procriação, nem comprometa o fim secundário. Pois, acarretando a incerteza da paternidade, tornaria impossivel o cumprimento do iniludivel dever da educação dos filhos. E S. Tomás conclui pela proïbição absoluta da poliandria: et ideo nulla lege aut consuetudine est permissum unam uxorem habere plures viros (63). Porque, se a lei natural não prescreve a

(63) Sent. IV, d. 33. q. 1 . a 1 in c. e ad $8^{\text {um }}$;a. 2 . Sent IV. d. 33 . q. 1 . a 1 in c. e ad $8^{\text {um }}$; a. 2 c., e ad $1^{\text {um }}$ e ad 2 um. - Cf. ainda: C. G. 3.123 e $124 ; S$. Th., 3. ${ }^{\mathrm{a}}$ supl. 65.1 c. e ad $8^{\mathrm{um}}$. , art. 2 e ad $4^{\mathrm{um}}$; Id., 1.2.105.4 ad $8^{\mathrm{um}}$; C. G., 3.123; super primam epistolam S. Pauli Apostoli ad Corinthios expositio, 8.1. Lotrin, Le Droit Naturel, ed. cit., pgs. $75,76,84,85,92 ;$ Id., La loi morale naturelle, ed. cit., pg. 38 n. 2; Deploige, op. cit., pg. 361 e segs,; Deploige, S. Thomas et la famile, in Annales de l'Institut Supérieur de Philosophie, Louvain, 19.24, t. V. pgs. 699 e segs. 
prática de todos os actos virtuosos, proíbe todos os actos maus: praecepto legis naturalis prohibentur ea quae sunt secundum se mala (64). Só o casamento monogámico é, portanto, a forma a satisfazer inteiramente às exigências tanto dos preceitos primários como dos secundários do direito natural.

c) A escravidão - Como do direito de propriedade, podemos dizer que a liberdade é de direito natural, porque o contrário - a escravidão, não o é. Pela razão natural ninguém é, particularmente, destinado a escravo (65). Não é, pois, a escravidão instituida por direito natural. Foi porém introduzida solum secundum aliquam utilitatem consequentem. Sendo assim, pertence ao ius gentium no sentido de Gaio, quod naturalis ratio inter omnes homines constituit. É natural, ao modo por que consideramos uma cousa proporcionada a outra relativamente, por uma conseqüência dela decorrente (66). Mas, certos, como os prisioneiros de guerra podem vir a ser escravos em virtude de uma lei positiva; e como hoc jure quasi omnes gentes utuntur, e se chama por isso ius gentium, conclui S. Tomás que a escravidão é um instituto do direito das gentes; tomada aqui a expressão antes no sentido que lhe deu Isidoro de Sevilha, e que se aproxima do moderno direito internacional público (67).

(64) Sent. IV, d. 15. q. 3. a. 1 sol. 4.

(65) S. Th.. 1.2.95.4 ad $3^{\text {um }}$; Id., 2.2.57.3 ad $2^{\text {um }}$. - E' verdade que em Pol. I, 3 e 4, S. Tomás sustenta que certos, per aptitudinem naturalem são naturaliter servi. Mas, como isso contradiz. abertamente a Summa, não poderíamos admitir senão que, comentando o pensamento de ARistóteles, nêsse lugar, S. Tomás apenas. o expõe objectivamente, sem lhe dar adesão. n. 4 .

(66) S. Th., 2.2.57.3 e ad $2^{\text {um }}$ - Cf. Jotrin, Droit Nat., 89,

(67) Pol. I, 4. - Cf. LotTin, Droit Nat. pg. 89, n. $4 . \quad$ o pensamento de S. Tomás se complica ainda quando diz (Sent 4. d. 36. q. 1. a. 1.) que a escravidão é contra primam intentionem naturae, i. é, contra os princípios primários da lei natural, mas não contra os secundários, sed non contra secundam. (Sôbre essa expressão - intentio, v. LotTrN, op. cit. pg. 77 n. 4). E a considera pena do pecado - servitus in poenam peccati introducta est, (ad- 
Esses três exemplos - da propriedade, do matrimónio e da escravidão, põem assim em evidência o pensamento. tomista sôbre a noção, a divisão e a imutabilidade do direito natural. Resta agora examinemos a noção de $l e i$, objecto de estudo subseqüente.

$2^{\text {um }}$.), determinada pelo direito positivo (civil). Sob êsse ângulo, pois, é do domínio dêste ramo do direito privado: determinare poenam. est juris positivi; et ideo servitus, quae est quaedam poena determinata, est de jure positivo, et a naturali profiscicitur sicut determinatum $\mathrm{ab}$ indeterminato $\left(\mathrm{ad} 3^{\mathrm{um}}\right.$.). - Como se vê, é flutuante o pensamento de S. Tomás, e julgamos que Carlyle tem razão, quando escreve: "it is not very easy to arrive at a confident judgement with regard to the whole of St. Thoma's position as regards slavery" (op. cit. V, 23). 